\title{
The Antimuscarinic Agent Tolterodine Regulates Bladder Extracellular Matrix in Partial Bladder Outlet Obstruction in Rats
}

\author{
Tong-Xin Yang a,b De-Yi Luo ${ }^{a} \quad$ Yi-Fei Lin ${ }^{a} \quad$ Qiang Liu ${ }^{a} \quad$ Xiang Cai ${ }^{a} \quad$ Jian-Zhong Ai ${ }^{a}$ \\ Hong Lia Hong Shen ${ }^{a}$ Kun-Jie Wanga \\ aDepartment of Urology, Institute of Urology (Laboratory of Reconstructive Urology), West China \\ Hospital, Sichuan University, Chengdu, Sichuan, 'Department of Urology, The Second Affiliated Hospital \\ of Kunming Medical University, Kunming, Yunnan, P. R. China
}

\section{Key Words}

Muscarinic receptor $•$ Extracellular matrix $•$ Bladder outlet obstruction $•$ Metalloprotease

\begin{abstract}
Background/Aims: Antimuscarinic agents can delay the progression of bladder dysfunction caused by bladder outlet obstruction (BOO). To date, the relationship between muscarinic receptor activity and the bladder extracellular matrix (ECM) remains unclear. Thus, an animal model of partial $\mathrm{BOO}$ (PBOO) in female rats was established to explore the variation in bladder wall ECM proteins under $\mathrm{PBOO}$ conditions with antimuscarinic agent administration. Methods: Rats were randomly divided into three groups: sham, PBOO, and PBOO plus tolterodine. Picrosirius red staining was used to examine the smooth muscle and collagen content of bladder samples. Gene microarray and RT-PCR were performed to survey the expression of ECM proteins, receptors, and metabolism regulators in the rat bladder. Positive results were further evaluated by immunohistochemistry. Results: Picrosirius red staining showed that smooth muscle volume significantly increased in the PBOO and PBOO plus tolterodine groups $(p<0.05)$, while collagen significantly increased in the PBOO group $(p<0.05)$ but not in the $\mathrm{PBOO}$ plus tolterodine group. Gene microarray and RT-PCR revealed that none of the collagen subtypes exhibited significant changes after PBOO establishment and tolterodine administration. However, matrix metalloproteinases (MMPs) increased significantly in the PBOO plus tolterodine group $(p<0.05)$. Additionally, PBOO inhibited the expression of noncollagen ECM proteins in the rat bladder wall, while tolterodine induced the expression of noncollagen ECM proteins and ECM receptors. Conclusions: Tolterodine decreased the volume of collagen in PBOO rat bladder wall, possibly via MMPs, and regulated the expression of ECM proteins and receptors.




\section{Cellular Physiology Cell Physiol Biochem 2018:46:36-45

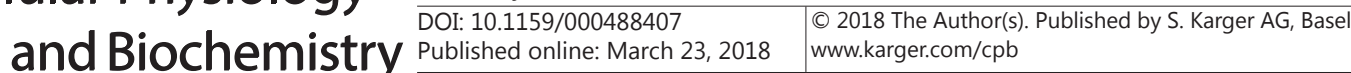 \\ Yang et al.: Tolterodine Regulates Bladder Extracellular Matrix}

\section{Introduction}

Bladder outlet obstruction (BOO) can result in structural and functional changes in the detrusor muscle of the bladder [1-3]. In the early stages of BO0, the bladder wall thickens to compensate for higher outlet resistance. However, over time, the detrusor muscle becomes decompensated and then lower urinary tract symptoms (LUTS) appear, ultimately progressing to urinary retention with overflow incontinence $[3,4]$.. Studies have shown that hypertrophy can be found in both smooth muscle cells and the extracellular matrix (ECM) of the bladder wall in BOO [5], where the ECM hypertrophy is mainly due to collagen accumulation, and the more collagen accumulates, the worse the LUTS are [6,7]. The main reason for collagen accumulation in the bladder wall in $\mathrm{BOO}$ is inhibited collagen catabolism rather than increased synthesis; this process is controlled by matrix metalloproteinases (MMPs) and tissue inhibitors of metalloproteinases (TIMPs) [8, 9]. An effective method for terminating or even reversing the morphological changes in the bladder wall is to relieve BOO as early as possible $[3,4]$. However, even if the obstruction is relieved, the existing collagen accumulation in the bladder wall and that of other non-collagen proteins is difficult to resolve completely, and in some patients, LUTS persist $[10,11]$. Therefore, a specific treatment to effectively activate collagen catabolism would be helpful for improving LUTS caused by long-standing BOO.

Acetylcholine, which activates muscarinic receptors on detrusor myocytes, is the main contractile transmitter of the bladder wall. A muscarinic antagonist can inhibit activation of muscarinic receptors, leading to decreased sensitivity of C-fibers and reduced involuntary contraction of the detrusor muscle at the urinary storage stage [12]. Thus, the bladder can achieve greater capacity with decreased urgency and frequency. Consequently, an antimuscarinic agent is effective for relieving LUTS caused by an overactive bladder. An antimuscarinic agent can also effectively improve LUTS caused by long-standing BOO because these symptoms are also caused by hypersensitive bladder filling and involuntary detrusor muscle contraction [3, 4]. Hence, an antimuscarinic agent does not just relieve the shortterm symptoms. A study on bronchial smooth muscle showed that prolonged action of an antimuscarinic agent remodeled the airway wall ECM, delayed smooth muscle hyperplasia, and changed the adhesive interaction between myocytes and ECM, ultimately improving the functional status of the airway smooth muscle [13]. The question is whether the prolonged effects of antimuscarinic agents can be obtained in the bladder, and whether the inhibition of muscarinic receptors can result in remodeling of the ECM and decomposition of collagen, consequently relieving LUTS caused by long-term BOO.

To address this, we established an animal model of partial BOO (PBO0) in SpragueDawley rats. The antimuscarinic agent tolterodine, was administered to the rats to examine differences in collagen accumulation and metabolism. Furthermore, expression of other noncollagen proteins and receptors in the bladder wall was examined to elucidate whether an antimuscarinic agent can affect the functional status of the bladder wall ECM as a therapeutic agent.

\section{Materials and Methods}

\section{Animals}

Female Sprague-Dawley rats (220 to $250 \mathrm{~g}$ ) were used. The rats had free access to water and food and were maintained in a temperature-controlled room under a 12-h light/dark cycle. The rats were randomly subdivided into three groups: sham, PBOO, and PBOO plus tolterodine $(0.36 \mathrm{mg} / \mathrm{kg})$, with five rats in each group. Tolterodine, a commonly used antimuscarinic agent, was dissolved in distilled water and administered by gavage. The sham and PBOO groups received the same volume of distilled water. Treatment was initiated on the first day after surgery and continued once daily for 3 weeks. All animal experiments were carried out in adherence with the National Institutes of Health Guidelines on the Use of Laboratory Animals and approved by the West China Hospital Committee on Animal Care. 


\section{Cellular Physiology Cell Physiol Biochem 2018;46:36-45 \begin{tabular}{l|l} 
and Biochemistry Published online: March 23, 2018 & $\begin{array}{l}\text { (c) } 2018 \text { The Author(s). Published by S. Karger AG, Basel } \\
\text { www.karger.com/cpb }\end{array}$
\end{tabular} \\ Yang et al.: Tolterodine Regulates Bladder Extracellular Matrix}

PBOO animal model

Rats were anesthetized by intraperitoneal injection of $0.9 \%$ chloral hydrate $(3 \mathrm{~mL} / \mathrm{kg})$. Then, a suprapubic midline incision was made to expose the bladder and proximal urethra. An urethra catheter (outer diameter: $1 \mathrm{~mm}$ ) was passed into the urethra and was then ligated with 4-0 silk around the proximal urethra to simulate PBOO. The catheter was then removed and the abdominal incision was closed. The sham group was subjected to the same procedure except for the urethra ligation. All the rats received $150 \mathrm{mg} / \mathrm{kg}$ body weight ampicillin intramuscularly after the procedure.

Microarray analysis

Microarray analysis (service provided by Kangchen Biotech, Shanghai, China) was performed to evaluate the bladder gene expression in the PBOO model and tolterodine-treated group using a Whole Rat Genome Oligo Microarray (Agilent Technologies, Santa Clara, CA).

Briefly, total RNA samples were isolated from rat bladder wall fragments using TRIzol Reagent (Life Technologies, Carlsbad, CA). Sample labeling and array hybridization were performed according to the OneColor Microarray-Based Gene Expression Analysis protocol (Agilent Technologies). In total, $100 \mu \mathrm{L}$ of the hybridized sample was dispensed into the gasket slide, which was then assembled with the gene expression microarray slide. Slides were incubated for $17 \mathrm{~h}$ at $65^{\circ} \mathrm{C}$ in an Agilent Hybridization Oven and scanned by the Agilent DNA Microarray Scanner (part number G2505C).

Agilent Feature Extraction software (version 11.0.1.1) was used to analyze acquired array images. Quantile normalization and subsequent data processing were performed using the GeneSpring GX v12.1 software package (Agilent Technologies). Differentially expressed genes with statistically significant differences between groups were identified and shown in Microsoft Excel documents.

\section{Reverse transcription polymerase chain reaction}

$\mathrm{RT}^{2}$ Profiler PCR Array (Agilent Technologies) was used to measure rat bladder ECM and adhesion molecule mRNA expression. Total RNA was isolated from fragments of rat bladder wall using TRIzol Reagent. RNA was eluted in $20 \mu \mathrm{L}$ nuclease-free water and stored at $-70^{\circ} \mathrm{C}$ until use. cDNA was synthesized using the iScript cDNA Synthesis Kit (Bio-Rad, Hercules, CA) according to the manufacturer's protocol. Reverse transcription and amplification were performed using $2 \times$ SuperArray PCR master mix (Agilent Technologies). PCR conditions were $95^{\circ} \mathrm{C}$ for $10 \mathrm{~min}$ and 40 amplification cycles $\left(95^{\circ} \mathrm{C}\right.$ for $15 \mathrm{~s}, 60^{\circ} \mathrm{C}$ for 1 min and optical read), followed by $95^{\circ} \mathrm{C}$ for $10 \mathrm{~s}$ and melting from $65^{\circ} \mathrm{C}$ to $95^{\circ} \mathrm{C}$ at $0.5^{\circ} \mathrm{C}$ per $5 \mathrm{~s}$. Data analysis was carried out using the comparative cycle threshold method with Bio-Rad iQ5 software.

\section{Histological analysis}

Bladder specimens were fixed in 4\% paraformaldehyde for $24 \mathrm{~h}$, then embedded in paraffin, cut into 4- $\mu \mathrm{m}$ sections, and mounted on microscope slides. The specimens were stained with picrosirius red to examine the smooth muscle and collagen content of the tissue. Images from each slide were captured using a digital camera (Olympus Corporation, Tokyo, Japan) in five randomly chosen areas at 100× magnification. The areas of collagen (red) and muscle tissue (yellow) were quantified using Image-Pro Plus (Media Cybernetics Inc., Rockville, MD). The integrated optical density (IOD) of smooth muscle or collagen was calculated and compared between groups.

\section{Immunohistochemistry}

For immunohistochemistry, fibronectin, integrin $\alpha 4$, integrin $\beta 2$, MMP7, and TIMP1 were detected using the following primary antibodies from Abcam (Cambridge, UK): rabbit anti-fibronectin (ab2413), rabbit anti-MMP7 (ab189277), rabbit anti-TIMP1 (ab61224), rabbit anti-integrin $\alpha 4$ (ab202969), and rabbit anti-integrin $\beta 2$ (anti-CD18, ab131044). The slides were stained according to the streptavidin-biotinperoxidase complex (SABC) method. Ten randomly chosen representative areas at $400 \times$ magnification from each section were captured and analyzed using Image-Pro Plus software. Immunohistochemical scores (IHS) were calculated and compared between groups.

\section{Statistical analysis}

Results are presented as the mean \pm standard deviation. Results between groups were compared by paired $t$ test or analysis of variance. A value of $p<0.05$ and fold-change $>1.5$ in microarray analysis was considered a difference requiring verification. A value of $p<0.05$ in the PCR and image analyses was considered significant. 


\section{Cellular Physiology Cell Physiol Biochem 2018;46:36-45

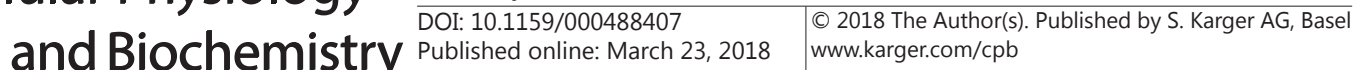 \\ Yang et al.: Tolterodine Regulates Bladder Extracellular Matrix}

\section{Results}

Collagen deposition in the $\mathrm{PBOO}$ rat bladder wall is relieved by tolterodine treatment

In the picrosirius red staining test, bladder wall thickness increased significantly after 3 weeks of PBOO. Furthermore, muscle area IOD increased by $121.4 \% \pm 55.7 \%(203.8 \pm 55.5$ vs. $92.1 \pm 34.0, p=0.009)$ and collagen increased by $64.4 \% \pm 25.4 \%$ ( $403.1 \pm 63.7$ vs. 245.2 $\pm 88.6, p=0.046$ ), compared with the sham group. When rats were treated with tolterodine for 3 weeks together with PBO0, the detrusor muscle IOD was significantly higher than that of the sham group $(269.6 \pm 43.7$ vs. $92.1 \pm 34.0, p<0.001)$, but there was no significant difference in the IOD compared with the PBOO group (269.6 \pm 43.7 vs. $203.8 \pm 55.5, p=$ 0.1 ). However, 3 weeks of tolterodine treatment together with PBOO reduced the rat bladder collagen IOD to the sham group level $(244.0 \pm 59.9$ vs. $245.2 \pm 88.6, p=0.858)$, which was significantly lower than that of the PBOO group $(244.0 \pm 59.9$ vs. $403.1 \pm 63.7, p=0.023$; Fig. 1 ). These results indicate that tolterodine either inhibited collagen synthesis or activated collagen catabolism in the PBOO bladder wall to reduce collagen accumulation.

Reduction in collagen volume is mediated by MMPs in the PBOO model rat with tolterodine treatment

Forty-six collagen gene transcripts were screened using an Agilent whole-genome microarray, of which 24 transcripts had potential expression differences between any two groups ( $p<0.05$, fold change $\geq 2$ ). These were further verified by PCR, but no significant difference was observed ( $p>0.05$; Fig. 2 ), suggesting that the accumulation of collagen in the PBOO rat bladder and the reduction in collagen volume in the PBOO plus tolterodine treatment rat bladder were not associated with collagen expression.

Fifty-three collagen metabolic regulator gene transcripts were screened by microarray, of which 22 transcripts had potential expression differences, and of these, 10 were further confirmed by PCR $(p<0.05$; Fig. 3A and $\mathrm{B})$. The results showed that antimuscarinic agent treatment of PBOO rats promoted an obvious increase in expression of MMPs (Adamts1, 2.04-fold, $p=0.047$; Mmp10, 3.55-fold, $p=0.004$; Mmp8, 5.56-fold, $p=0.013 ;$ Mmp9, 5.96-fold, $p=0.046$ ), and in Timp1 (3.92-fold, $p=0.045$ ). Compared with the PBOO plus tolterodine group and the sham group, there was also a significant increase in Adamts8 (19.47-fold, $p=0.006$ ), Mmp7 (457.24-fold, $p<0.001$ ), and Mmp13 (3.40-fold, $p=0.025$ ) expression. These results suggest that tolterodine promoted the gradual decomposition of accumulated collagen in the PBOO rat bladder by regulating the expression of MMPs and TIMPs.

This increased expression, as well as the distribution, of MMP7 and TIMP1 in each group was further examined by

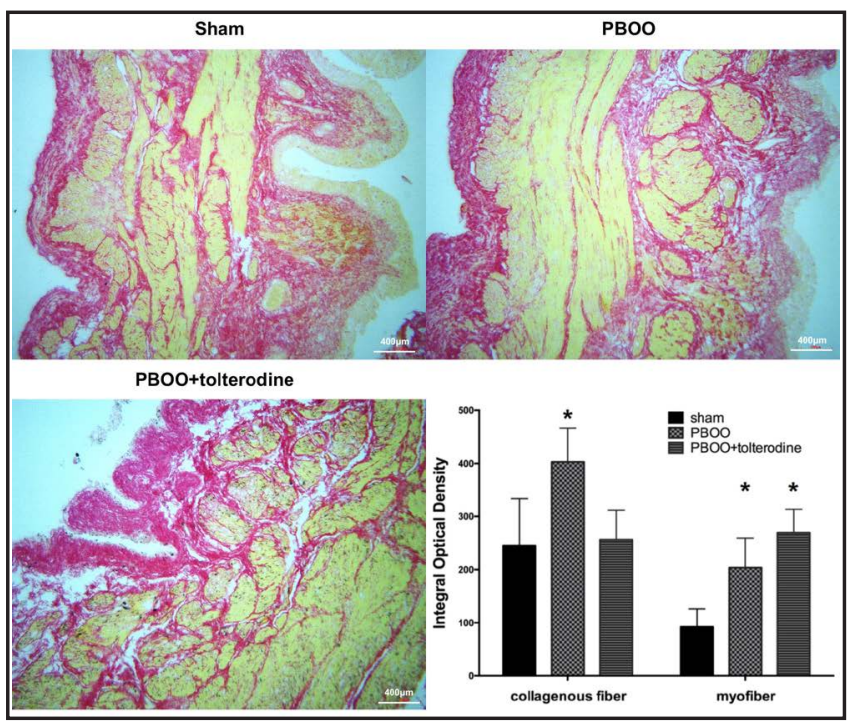

Fig. 1. Rat bladder paraffin sections stained with picrosirius red. Red-stained areas in the muscular layer represent collagen fibers, and yellow stained areas represent myofibers. Each sample slide was captured in five randomly chosen areas at $100 \times$ magnification and analyzed using Image-Pro Plus. Smooth muscle or collagen IOD was calculated and is shown in the histogram. Tolterodine can either inhibit collagen synthesis or activate collagen catabolism in the PBOO bladder wall to relieve collagen accumulation. ${ }^{*} \mathrm{p}<0.05$ compared with the sham group. Scale bar is $400 \mu \mathrm{m}$. 


\section{Cellular Physiology and Biochemistry}

Cell Physiol Biochem 2018;46:36-45

\begin{tabular}{l|l}
\hline DOI: $10.1159 / 000488407$ & (c) 2018 The Author(s). Published by S. Karger AG, Basel
\end{tabular}

Yang et al.: Tolterodine Regulates Bladder Extracellular Matrix immunohistochemistry. MMP7 and TIMP1 were mainly distributed in the ECM (Fig. 3C). Compared with the sham group, the MMP7 IHS in the PBOO group was 1.22-fold higher $(p=0.038)$ and that of TIMP1 was 1.54 -fold higher $(p=0.086)$; the MMP7 IHS in the PBOO plus tolterodine group was 2.06fold higher $(p=0.036)$ and that of TIMP1 was 2.62-fold higher ( $p=0.013$; Fig. 3D). These results support the abovementioned changes in gene expression.

Tolterodine promotes
expression of noncollagen ECM proteins and ECM receptors

Gene expression of non-collagen ECM proteins in the PBOO rat bladder with tolterodine treatment significantly changed compared with the PBOO

Fig. 3. Expression of matrix metalloproteinases and their inhibitors in rat bladder wall upon $\mathrm{PBOO}$ modeling and antimuscarinic agent treatment evaluated by rat genome-wide microarray analysis (A), RT-PCR (B) and immunohistochemistry (C). Tissue samples were stained with-MMP7 and -TIMP1 antibodies using the SABC method. Each slide was captured in 10 randomly chosen areas at $400 \times$ magnification and analyzed using Image-Pro Plus. The IHS was calculated and is shown in the histogram (D). Tolterodine can promote gradual decomposition of accumulated collagen in PBOO rat bladder by regulating the expression of MMPs and TIMPs. ${ }^{*} \mathrm{p}<0.05$ compared with the sham group. Scale bar is $100 \mu \mathrm{m}$.
Fig. 2. Collagen gene expression of the rat bladder wall upon PBOO modeling and antimuscarinic agent treatment evaluated by rat genome-wide microarray analysis (A) and RT-PCR (B). Accumulation of collagen in the PBOO rat bladder and reduction in collagen volume in the PBOO plus tolterodine treatment rat bladder are not associated with collagen expression.
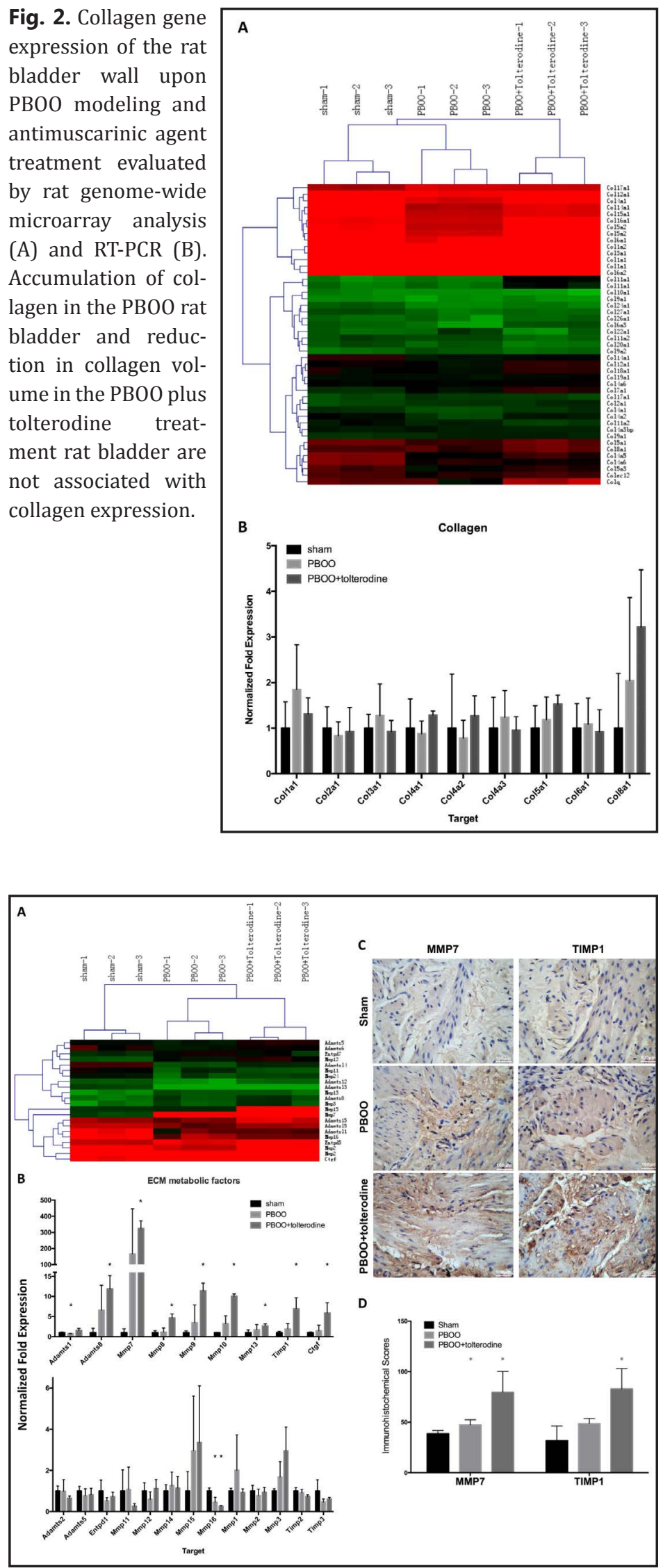
Fig. 4. Expression of cell adhesion molecules in rat bladder wall upon PBOO and antimuscarinic agent treatment evaluated by rat genome-wide microarray analysis (A), RT-PCR (B), and immunohistochemistry study (C). Tissue samples were stained with an anti-fibronectin antibody using the SABC method. The IHS was calculated and is shown in the histogram (D). ${ }^{*} \mathrm{p}<0.05$ compared with the sham group. Scale bar is $100 \mu \mathrm{m}$.

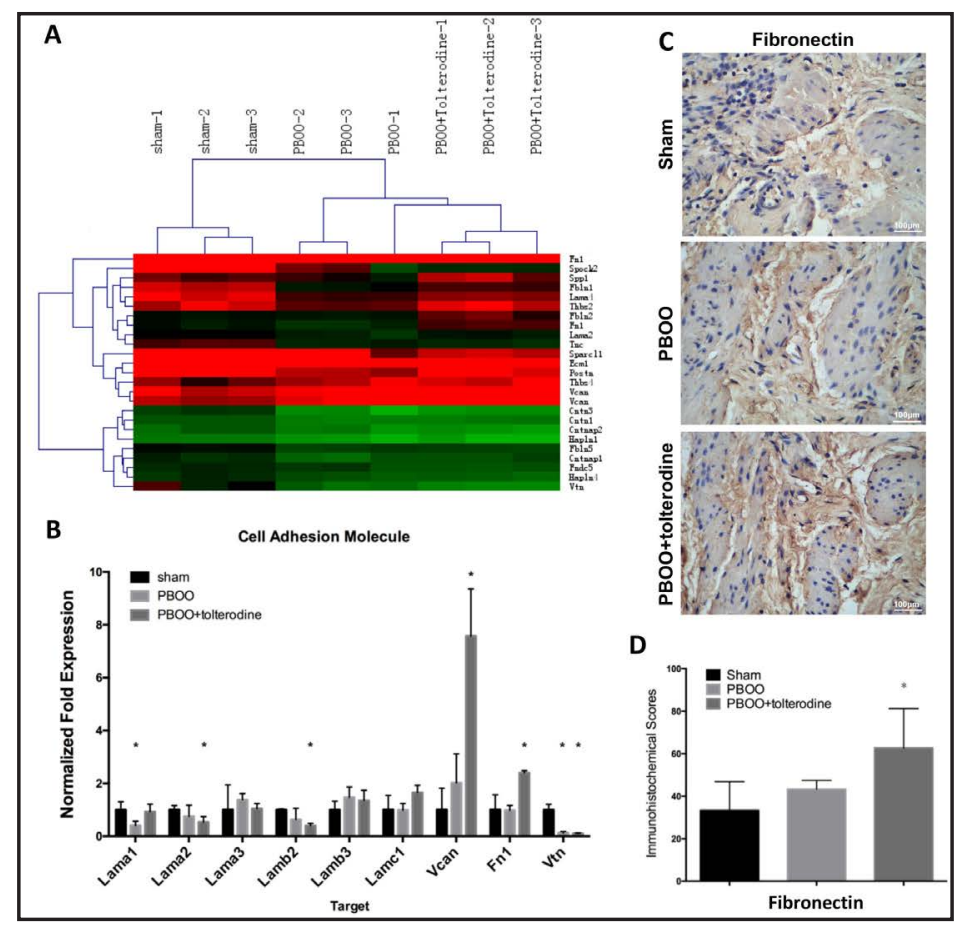

Fig. 5. Expression of ECM receptors in rat bladder wall upon $\mathrm{PBOO}$ and antimuscarinic agent treatment evaluated by rat genomewide microarray analysis (A), RTPCR (B), and immunohistochemistry study (C). Tissue samples were stained with anti-integrin $\alpha 4$ and -integrin $\beta 2$ antibodies using the SABC method. The IHS was calculated and is shown in the histogram (D). *p<0.05 compared with the sham group. Scale bar is $100 \mu \mathrm{m}$.

group. Forty ECM noncollagen transcripts were screened by microarray, and 25 of these showed potential differences between any two

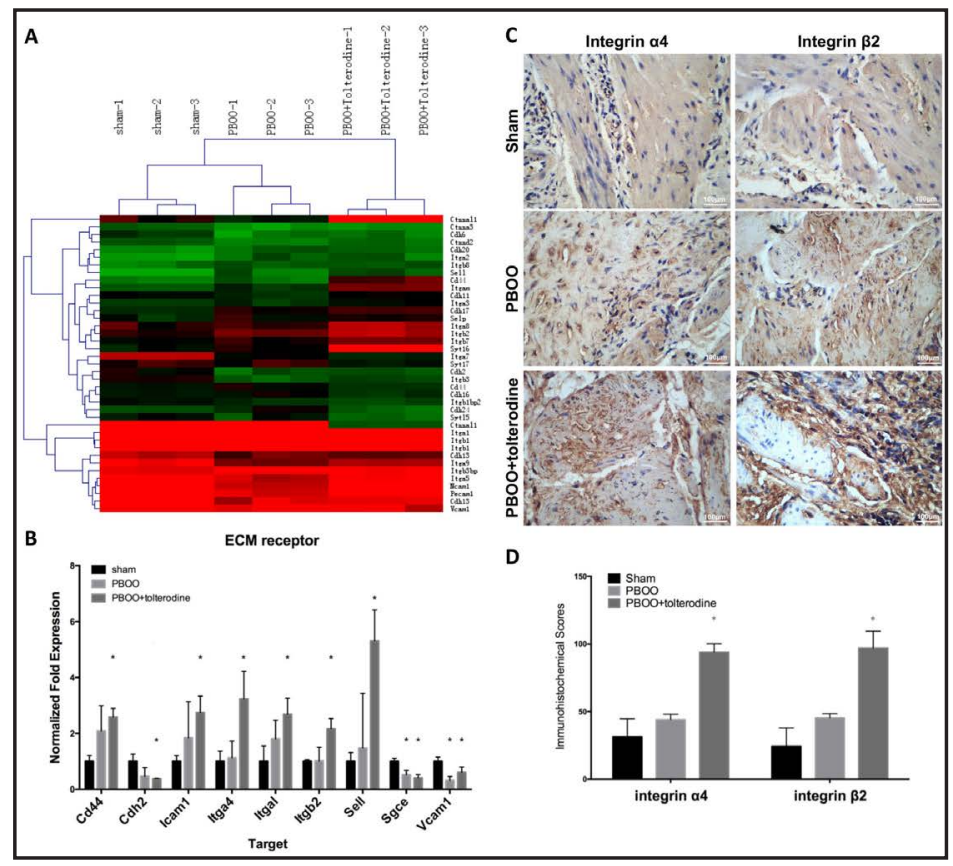
groups ( $p<0.05$, fold change $\geq 2$ ). Of these 25, 13 ECM transcripts were further confirmed by PCR ( $p<0.05$; Fig. $4 \mathrm{~A}$ and B). PBOO mainly downregulated the expression of non-collagen ECM mRNAs (Hapln1, -9.00fold, $p=0.038 ;$ Lama1, -2.60 -fold, $p=0.039$; Postn, -2.17 -fold, $p=0.002$; Thbs2, -2.11 -fold, $p$ $=0.004 ;$ Tnc, -2.60 -fold, $p=0.006$; Vtn, -8.30 -fold, $p=0.002$ ), and the antimuscarinic agent upregulated the expression of non-collagen ECM mRNAs (Fn1, 2.48-fold, $p<0.001$; Postn, 2.39-fold, $p=0.013$; Spp1, 7.67-fold, $p=0.015$; Vcan, 4.04-fold, $p=0.010$ ).

Tolterodine treatment promoted expression of ECM receptor genes. Thirty-nine transcripts with potential differences were screened from 87 ECM receptor gene transcripts by microarray; of these 11 ECM receptors were confirmed to have significant expression 


\section{Cellular Physiology Cell Physiol Biochem 2018;46:36-45 \\ and Biochemistry Published online: March 23, $2018 \quad \begin{aligned} & \text { DOI: 10.1159/000488407 } 2018 \text { The Author(s). Published by S. Karger AG, Basel } \\ & \text { www.karger.com/cpb }\end{aligned}$ \\ Yang et al.: Tolterodine Regulates Bladder Extracellular Matrix}

changes after further PCR validation ( $p<0.05$; Fig. $5 \mathrm{~A}$ and $\mathrm{B})$. The results showed that the expression changes in ECM receptor genes in the bladder wall were not significant in the PBOO group; however, tolterodine treatment increased the expression of Itgb4 3.08-fold ( $p$ $=0.034)$, Itgb2 2.28-fold ( $p=0.032)$, and Sell 7.32-fold ( $p=0.042)$.

The increased expression and distribution of fibronectin (Fn1), integrin $\alpha 4$ (Itga4), and integrin $\beta 2$ (Itg b2) in tissue slices from each group was examined by immunohistochemistry. Fibronectin was mainly distributed in the ECM (Fig. 4C). Compared with the sham group, the fibronectin IHS in the PBOO group did not significantly change $(p=0.165)$; however, in the PBO0 plus tolterodine group it was increased 1.88-fold ( $p=0.049$; Fig. 4D). integrin $\alpha 4$ and integrin $\beta 2$ were mainly distributed in the plasma membrane (Fig. $5 \mathrm{C}$ ). Compared with the sham group, the integrin $\alpha 4(p=0.118)$ and integrin $\beta 2(p=0.055)$ IHS in the PBO0 group showed no significant change. However, the integrin $\alpha 4$ IHS was increased in the PBOO plus tolterodine group 3.00-fold ( $p=0.003)$ and integrin $\beta 2$ was increased 3.99-fold ( $p=0.001$; Fig. 5D). These results support the abovementioned changes in gene expression.

\section{Discussion}

The rat PBOO model is a common pathological model for research on bladder function. This animal model has a defined modeling scheme that can be easily implemented, with significant differences between the experimental group and the control group. The rat PBOO model was initially established by Mattiasson and colleagues [14]. After several attempts, the 1-mm-catheter-guided partial ligation of the female rat urethra, which does not totally close the urethra and improves bladder outlet resistance, was adopted. Shakirova and colleagues [15] have reported that shortly after establishing a PBOO model, the weight of the detrusor muscle may increase rapidly; the weight of the bladder increased from $80 \mathrm{mg}$ to $480 \mathrm{mg}$ after 6 weeks of obstruction. The increase in detrusor muscle weight is mainly due to smooth muscle cell hypertrophy in the bladder, while there is relatively less hyperplasia. The crosssectional area of smooth muscle cells after 6 weeks of obstruction may increase 10-fold [16]. At this point, a urodynamic test may result in elevated maximal micturition pressure, increased residual urine, increased frequency of detrusor muscle contractility, and reduced bladder wall compliance [17]. Relieving the BOO state is the most effective means of curbing the development of this condition. However, if BOO persists for a long time, the resultant structural changes and bladder wall dysfunction may not be completely alleviated $[10,11]$.

Bladder wall dysfunction is associated with metabolic disorders of bladder wall ECM [18]. BOO causes strain injury to the bladder wall, leading to rupture of collagen fibers, which gradually break down into short-chain collagens that are deposited in the intercellular space [19]. Because of the sustained BOO, the newly synthesized collagen fibers will gradually decompose into short-chain collagens, leading to gradual aggravation of collagen deposition; short-chain collagens lack good elasticity, and along with the increase in collagen deposition, the ECM gradually loses its elasticity, resulting in deceased bladder wall constriction and compliance $[6,7,19]$. Several clinical and pathological studies have pointed out that the $\mathrm{ECM} /$ cell ratio is an important indicator of bladder function $[18,20,21]$. The higher the ratio, the poorer the bladder compliance and the more severe the patient's LUTS. Therefore, in addition to the early relief of the BOO state, identifying a therapeutic strategy for promoting collagen decomposition will help relieve the strain injury to the bladder wallcaused by BOO.

Acetylcholine muscarinic $M_{2}$ and $M_{3}$ receptors are the main cause of bladder detrusor muscle contraction; thus, blocking the effect of acetylcholine on muscarinic receptors can relax the detrusor muscle. Conventionally, highly selective $\mathrm{M}_{2}$ and $\mathrm{M}_{3}$ receptor antagonists have been used to treat overactive bladder and detrusor hyperreflexia. Commonly used drugs include the $M_{2}$ and $M_{3}$ receptor antagonist tolterodine and the $M_{3}$ receptor antagonists Solifenacin and Darifenacin, all of which are competitive antagonists [3, 4]. An antimuscarinic agent can also be used for alleviating LUTS secondary to BOO, because BOO can also cause detrusor overactivity. In fact, the use of an antimuscarinic agent for treating detrusor 


\section{Cellular Physiology Cell Physiol Biochem 2018;46:36-45 \begin{tabular}{l|l|l} 
and Biochemistry 10.1159/000488407 & $\begin{array}{l}\text { (c) 2018 The Author(s). Published by S. Karger AG, Basel } \\
\text { www.karger.com/cpb }\end{array}$
\end{tabular} \\ Yang et al.: Tolterodine Regulates Bladder Extracellular Matrix}

overactivity associated with benign prostatic hyperplasia had a better curative effect than expected. Most patients may develop a new balance between urine storage and voiding after drug administration, and even maintain a good quality of life after drug discontinuation $[22,23]$. This suggests that antimuscarinic agents may have more profound effects on the bladder wall. However, a review of the literature revealed that this research direction has not attracted much attention.

The results of the present study preliminarily confirmed the curative effect of antimuscarinic agents on the pathological status of the rat bladder wall ECM in the PBOO model. According to the rat whole-genome microarray and PCR verification analyses, deposition and decomposition of collagen in the bladder wall are not associated with collagen synthesis. By upregulating the expressioin of MMP to promote the gradual decomposition of deposited collagen in the rat bladder wall in the PBOO model, an antimuscarinic agent is an effective means for changing the bladder wall ECM/cell ratio. This result associates muscarinic receptors with the catabolism of bladder wall ECM. Inhibiting muscarinic receptor activity is no longer a therapeutic strategy for just alleviating symptoms. It can also slow down and even impede damage to the bladder wall ECM caused by BOO, consistent with its clinical efficacy.

We may regard the rat PBOO model as an effective scheme for applying biomechanical force on the bladder wall in vivo. In experiments incorporating mechanical strain on bladder smooth muscle cells in vitro, we tried to identify the most favorable method and parameters of strain loading for cell proliferation [24-26]. The in vitro experimental model is unique, with vast differences in the mechanical environment compared with the in vivo condition [27], so it is impossible to describe strain-loading parameters in vitro in simple physiological or pathological terms. The rat PBOO model is closer to the real mechanical environment of the bladder wall. Specifically, the sham group can be regarded as a physiological biomechanics model, the PBOO group can be regarded as a pathological biomechanics model, and the PBOO plus tolterodine group can be regarded as a pathological biomechanics model with drug treatment to slow down ECM lesions.

The expression of cell adhesion molecules and matrix receptor proteins under rat bladder wall strain and medication mode showed the following: (1) Vtn was downregulated upon PBOO pathological strain, and it was still downregulated after treatment with tolterodine, suggesting that there is no definite relationship between Vtn and rat bladder wall function. Fn1 showed no obvious change upon pathological strain, but its expression was significantly increased after treatment with tolterodine. Furthermore, immunohistochemical staining showed that fibronectin expression increased after treatment with tolterodine, suggesting that fibronectin expression is closely associated with bladder ECM function. 2) Most of the ECM receptor proteins showed no obvious changes upon PBOO pathological strain, but the expression of some matrix receptors (Cd44, Icam1, Sell, Itga4, Itga1 and Itgb2) remarkably increased following tolterodine treatment. Immunohistochemical staining showed that the expression of integrin subtypes $\alpha 4$ and $\beta 2$ also increased, suggesting that the expression of matrix receptor proteins is associated with bladder ECM function. The above results indicate that the increased expression of cell adhesion molecules and matrix receptor proteins has important implications in the effect of tolterodine on the bladder wall ECM in ameliorating PBO0.

\section{Conclusion}

Antimuscarinic agents can decrease the volume of collagen in the PBOO rat bladder. They are also effective for reducing the ECM/cell ratio under such pathological conditions. Because tolterodine both increased the expression of MMPs and promoted degradation of collagen fibers, we considered that the volume of collagen was decreased via MMPs. Concurrently, antimuscarinic agents can regulate the expression of ECM proteins and receptors. Such a relationship between muscarinic receptors and bladder wall ECM is likely to be associated with the functional status of the bladder wall. 


\section{Cellular Physiology Cell Physiol Biochem 2018;46:36-45 and Biochemistry Published online: March 23, 2018 \begin{tabular}{l|l} 
DOI: 10.1159/000488407 & $\begin{array}{l}\text { (c) } 2018 \text { The Author(s). Published by S. Karger AG, Basel } \\
\text { www.karger.com/cpb }\end{array}$
\end{tabular} \\ Yang et al.: Tolterodine Regulates Bladder Extracellular Matrix}

\section{Acknowledgements}

This study was supported by Grant No. 31170907, No. 31370951, No. 81470927, No.81300579 and No.81770673 from the National Natural Science Foundation of China, Grant No. JH2015017 from the Application-oriented Foundation of Committee Organization Department of Sichuan Provincial Party, and the 1.3.5 Project for Disciplines of Excellence, West China Hospital, Sichuan University.

\section{Disclosure Statement}

There are no competing financial interests to declare.

\section{References}

1 Galosi AB, Mazzaferro D, Lacetera V, Muzzonigro G, Martino P, Tucci G: Modifications of the bladder wall (organ damage) in patients with bladder outlet obstruction: ultrasound parameters. Arch Ital Urol Androl 2012;84:263-267.

2 Tubaro A, Mariani S, De Nunzio C, Miano R: Bladder weight and detrusor thickness as parameters of progression of benign prostatic hyperplasia. Curr Opin Urol 2010;20:37-42.

-3 Gormley EA, Lightner DJ, Faraday M, Vasavada SP, American Urological A, Society of Urodynamics FPM: Diagnosis and treatment of overactive bladder (non-neurogenic) in adults: AUA/SUFU guideline amendment. J Urol 2015;193:1572-1580.

-4 Gratzke C, Bachmann A, Descazeaud A, Drake MJ, Madersbacher S, Mamoulakis C, Oelke M, Tikkinen KA, Gravas S: EAU Guidelines on the Assessment of Non-neurogenic Male Lower Urinary Tract Symptoms including Benign Prostatic Obstruction. Eur Urol 2015;67:1099-1109.

-5 Collado A, Batista E, Gelabert-Mas A, Corominas JM, Arano P, Villavicencio H: Detrusor quantitative morphometry in obstructed males and controls. J Urol 2006;176:2722-2728.

-6 Kaplan EP, Richier JC, Howard PS, Ewalt DH, Lin VK: Type III collagen messenger RNA is modulated in noncompliant human bladder tissue. J Urol 1997;157:2366-2369.

-7 Yang L, He DL, Wang S, Cheng HP, Wang XY: Effect of long-term partial bladder outlet obstruction on caldesmon isoforms and their correlation with contractile function. Acta Pharmacol Sin 2008;29:600-605. Jablonska-Trypuc A, Matejczyk M, Rosochacki S: Matrix metalloproteinases (MMPs), the main extracellular matrix (ECM) enzymes in collagen degradation, as a target for anticancer drugs. J Enzyme Inhib Med Chem 2016;31:177-183.

-9 Van Doren SR: Matrix metalloproteinase interactions with collagen and elastin. Matrix Biol 2015;4446:224-231.

10 Hakenberg OW, Pinnock CB, Marshall VR: The follow-up of patients with unfavourable early results of transurethral prostatectomy. BJU Int 1999;84:799-804.

-11 Shin YS, Zhang LT, You JH, Choi IS, Zhao C, Park JK: Efficacy and safety of tamsulosin hydrochloride $0.2 \mathrm{mg}$ and combination of tamsulosin hydrochloride $0.2 \mathrm{mg}$ plus solifenacin succinate $5 \mathrm{mg}$ after transurethral resection of the prostate: a prospective, randomized controlled trial. Clin Interv Aging 2016;11:1301-1307.

12 Athanasopoulos A, Cruz F: The medical treatment of overactive bladder, including current and future treatments. Expert Opin Pharmacother 2011;12:1041-1055.

-13 Karakiulakis G, Roth M: Muscarinic receptors and their antagonists in COPD: anti-inflammatory and antiremodeling effects. Mediators Inflamm 2012;2012:409580.

14 Mattiasson A, Uvelius B: Changes in contractile properties in hypertrophic rat urinary bladder. J Urol 1982;128:1340-1342.

15 Shakirova Y, Sward K, Uvelius B, Ekman M: Biochemical and functional correlates of an increased membrane density of caveolae in hypertrophic rat urinary bladder. Eur J Pharmacol 2010;649:362-368.

16 Gabella G, Uvelius B: Urinary bladder of rat: fine structure of normal and hypertrophic musculature. Cell Tissue Res 1990;262:67-79. 


\section{Cellular Physiology Cell Physiol Biochem 2018;46:36-45

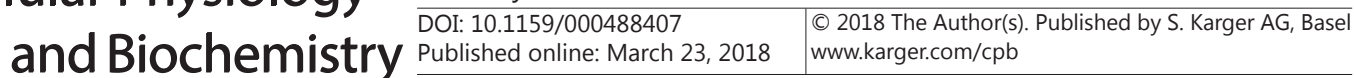 \\ Yang et al:: Tolterodine Regulates Bladder Extracellular Matrix}

17 Malmgren A, Sjogren C, Uvelius B, Mattiasson A, Andersson KE, Andersson PO: Cystometrical evaluation of bladder instability in rats with infravesical outflow obstruction. J Urol 1987;137:1291-1294.

18 Aitken KJ, Bagli DJ: The bladder extracellular matrix. Part I: architecture, development and disease. Nat Rev Urol 2009;6:596-611.

19 Levin RM, O'Connor LJ, Leggett RE, Whitbeck C, Chichester P: Focal hypoxia of the obstructed rabbit bladder wall correlates with intermediate decompensation. Neurourol Urodyn 2003;22:156-163.

20 Oh MM, Choi H, Park MG, Kang SH, Cheon J, Bae JH, Moon du G, Kim JJ, Lee JG: Is there a correlation between the presence of idiopathic detrusor overactivity and the degree of bladder outlet obstruction? Urology 2011;77:167-170.

21 Vella M, Robinson D, Cardozo L, Srikrishna S, Cartwright R: Predicting detrusor overactivity using a physician-based scoring system. Int Urogynecol J Pelvic Floor Dysfunct 2008;19:1223-1227.

22 Greco KA, McVary KT: The role of combination medical therapy in benign prostatic hyperplasia. Int J Impot Res 2008;20:S33-43.

23 Verheggen BG, Lee R, Lieuw On MM, Treur MJ, Botteman MF, Kaplan SA, Trocio JN: Estimating the qualityof-life impact and cost-effectiveness of alpha-blocker and anti-muscarinic combination treatment in men with lower urinary tract symptoms related to benign prostatic hyperplasia and overactive bladder. J Med Econ 2012;15:586-600.

24 Tian Y, Yue X, Luo D, Wazir R, Wang J, Wu T, Chen L, Liao B, Wang K: Increased proliferation of human bladder smooth muscle cells is mediated by physiological cyclic stretch via the PI3KSGK1Kv1.3 pathway. Mol Med Rep 2013;8:294-298.

25 Chen L, Wu T, Wei TQ, Wei X, Li SF, Wang KJ, Li H: Skp2-mediated degradation of p27 regulates cell cycle progression in compressed human bladder smooth muscle cells. Kaohsiung J Med Sci 2014;30:181-186.

-26 Chen L, Wei TQ Wang Y, Zhang J, Li H, Wang KJ: Simulated bladder pressure stimulates human bladder smooth muscle cell proliferation via the PI3K/SGK1 signaling pathway. J Urol 2012;188:661-667.

-27 Lu S, Wang Y: Single-cell imaging of mechanotransduction in endothelial cells. Prog Mol Biol Transl Sci 2014;126:25-51. 